\title{
Distribución de plantas vasculares a escala local. Taxones con mayor ocupación geográfica en Ambite y Utande (La Alcarria Occidental)
}

\author{
Flowering plant distributions at local scale. \\ Taxa with most spatial cover in Ambite and Utande \\ (Western "La Alcarria")
}

\author{
Juan Javier García-Abad Alonso ${ }^{1}$
}

\section{INTRODUCCIÓN}

La abundancia, frecuencia y riqueza de especies expresan propiedades geográficas de los organismos vivos que la Biogeografía y Ecología han tratado continuamente como temas de interés habitual. Igualmente el conocimiento y análisis de la distribución de esos organismos, en tanto en cuanto sintetiza la situación y estado en un momento dado del conjunto de factores intrínsecos y extrínsecos, abióticos y bióticos, actuales e históricos que determinan su dinámica vital, han sido también objeto de estudio permanente. Pero, a diferencia de aquellas primeras cuestiones, esas áreas de distribución se erigen como el tema de más genuino significado biogeográfico (If there is any basic unit of biogeography, it is the geographic range of a species refieren literalmente Brown et al., 1996: 597). Este artículo trata sobre tales distribuciones en plantas vasculares a escala local, empleando la cuadrícula UTM $1 \times 1 \mathrm{~km}($ ED50) como unidad de información, en dos cuadrículas de 10×10 km de La Alcarria Occidental.

\footnotetext{
${ }^{1}$ Departamento de Geología, Geografía y Medio Ambiente, Universidad de Alcalá de Henares.juanj.garciaabad@uah.es
} 
En un artículo previo de esta Revista (García-Abad, 2015), se han explicado ya los planteamientos de partida, el método empleado y la formulación de dos índices de ocupación de la flora (IOP e IOF). Como continuación a esa labor, el objetivo fundamental del presente artículo es mostrar y comentar distribuciones geográficas de la presencia y abundancia de algunas de las plantas encontradas.

La representación de distribuciones florísticas con resolución de cuadrículas de $10 \times 10 \mathrm{~km}$ es hoy en día bastante habitual, tal y como revela la generalización de bases de datos biogeográficas que la emplean (ORCA -Bolòs, 1985-, Anthos, SIVIM, etc.) y bastantes publicaciones. Sin embargo, aunque no es nuevo, el empleo de la resolución con cuadrículas de $1 \times 1 \mathrm{~km}$ ha sido bastante menos desarrollado debido al esfuerzo de trabajo de campo que requiere.

Siguiendo métodos descriptivos de la Biogeografía Comparativa (Parenti y Malte, 2009) y teniendo en cuenta el contexto y antecedentes del método (Panareda y Nuet, 1993-94; Meaza, 2000 y García-Abad et al., 2009, entre otras publicaciones); los objetivos específicos de este artículo son: a) exponer los factores geográficos que inciden en la distribución de especies en las dos áreas de estudio; b) presentar mediante cartografía corológica la distribución de los doce taxones que tienen el mayor Índice de Ocupación de la Planta (IOP) en el conjunto de las dos cuadrículas analizadas; c) representar las distribuciones con tres resoluciones cartográficas diferentes ( 1,4 y $25 \mathrm{~km}^{2}$ ), además del resultado global en la cuadrícula de $100 \mathrm{~km}^{2}$; y d) comentar las distribuciones obtenidas de manera comparada desde un punto de vista fitogeográfico, tanto internamente planta a planta dentro de cada cuadrícula, como bilateralmente entre ambas cuadrículas.

\section{MATERIALES Y MÉTODO}

Para aplicar el método propuesto se eligieron dos cuadrículas UTM de 10×10 km (ED50): la 30TWL02 (denominada Utande), al norte, y la 30TVK86 (Ambite), al sur. Ambas pertenecen a la subprovincia biogeográfica ("Castellana", según Rivas-Martínez, 2007), a la subregión natural ("La Alcarria Occidental”, según García-Abad, 2006) y, por tanto, poseen pautas paisajísticas similares (páramos y mesas y, en menor medida, campiñas, según Mata y Sanz, 2003). De este modo, se pueden comparar los resultados obtenidos en dos áreas relativamente similares, pero diferenciadas por encontrarse suficientemente separadas entre sí y ocupar sectores con algunos rasgos geográficos distintivos (figura 1): 
FIGURA 1

MAPAS Y SITUACIÓN DE LAS DOS ÁREAS DE ESTUDIO

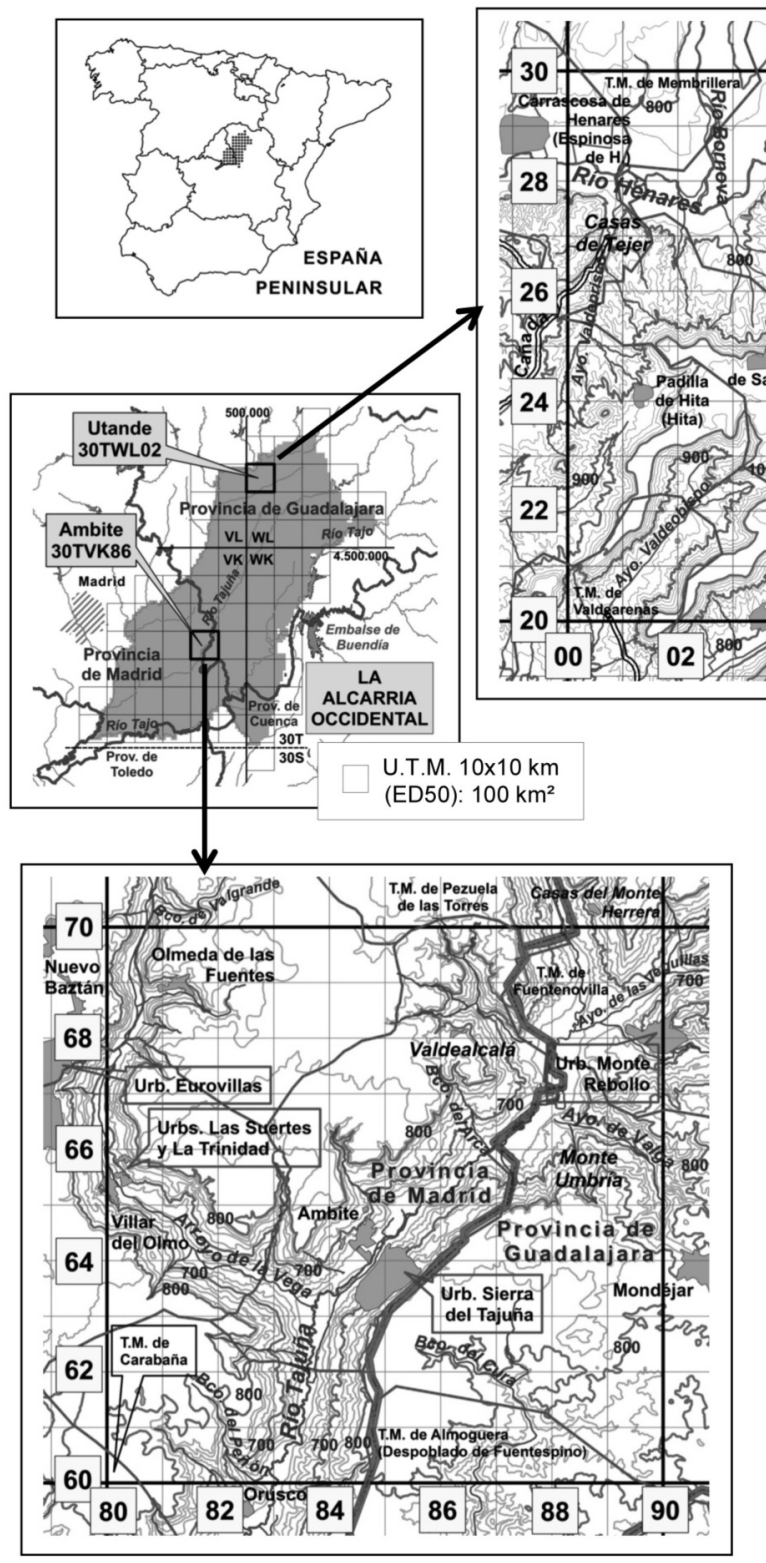

Limite Municipal

Límite Provincial

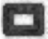

Núcleo Población

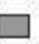

Curva de nivel

Río, arroyo

Equidistancia de las Curvas de Nivel $(20 \mathrm{~m})$, Maestras $(100 \mathrm{~m})$

$1 \mathrm{~km}^{2}$ U.T.M. $1 \times 1 \mathrm{~km}(\mathrm{ED} 50)$

T.M. Término Municipal

Fuente: Compuesto a partir de la BCN25 (I.G.N.). 
De acuerdo al método de trabajo expuesto en el artículo anterior (GarcíaAbad, 2015), en Utande se inventarió la flora por separado en las 100 cuadrículas de $1 \mathrm{~km}^{2}$. Sin embargo, en Ambite se inventariaron 98, porque no se pudo entrar en dos de ellas al estar completamente dentro de fincas privadas y con acceso no permitido por vallado.

\section{Factores geográficos en Ambite y Utande}

Para entender la distribución y abundancia de las plantas a escala local, es preciso exponer ampliamente los rasgos geográficos que influyen en su configuración. La exposición que sigue transcribe parcialmente la ya efectuada para Utande en García-Abad et al. (2009: 162-164), pero añadiendo los rasgos de Ambite, algunos comentarios comparativos; y adaptando y reordenando en su caso algunos términos.

\section{Factores del medio físico}

Utande se sitúa en la comarca de la Alta Alcarria y en el sector biogeográfico "Celtibérico-Alcarreño", subsector "Alcarreño" (Rivas-Martínez, 2007). $\mathrm{Su}$ altitud oscila entre 1050 y 765 m s.n.m. Bioclimáticamente (RivasMartínez y Loidi, 1999 y Rivas-Martínez et al., 2002), la mayor parte de ella se encuentra en el piso supramediterráneo; pero, en algunas laderas con exposición solana y partes bajas, se encuentran áreas propias del piso mesomediterráneo. Los valores promedio del Índice de termicidad compensado (Itc) están entre 200 y 205, y los de Temperatura positiva anual (Tp) entre 1485 y 1505, pudiendo ser un poco más elevados en las áreas más térmicas. El Índice ombrotérmico anual (Io) seco superior ${ }^{2}$.

Ambite se sitúa en la Baja Alcarria, y en el sector biogeográfico "Manchego" y subsector "Manchego Sagrense". Su altitud oscila entre 864 y 610 m s.n.m. Bioclimáticamente, la mayor parte de ella se encuentra en el piso mesomediterráneo; pero, en los páramos más elevados del N y NW, y en algunas laderas con exposición umbrosa, se encuentran áreas propias de un

\footnotetext{
${ }^{2}$ Los valores bioclimáticos (y los climáticos que se refieren más adelante) son aproximaciones que se basan en cálculos efectuados en García-Abad (2006) y García-Abad et al. (2009) con datos del antiguo Instituto Nacional de Meteorología (series diversas dentro del periodo 1951-2000).
} 
incipiente piso supramediterráneo. Los valores promedio de Itc están entre 210 y 220 , y los de Tp entre 1515 y 1535, pudiendo ser un poco menos elevados en las áreas menos térmicas. El ombroclima es también seco superior (Io entre 3,3 y 3,1 ).

En ambas cuadrículas el clima es mediterráneo con matiz continental, térmicamente muy contrastado y afectado por inversiones térmicas de diferente intensidad. La temperatura media anual varía un poco entre Utande y Ambite $\left(12-13^{\circ} \mathrm{C}\right.$ y $12,5-14$ respectivamente), al igual que la precipitación media anual (450-550 $\mathrm{mm}$ y 425-500, respectivamente).

Geológicamente, ambas pertenecen a la Depresión del Tajo, presentan variación de facies y litologías sedimentarias de edad neógena, aunque son las calizas las que dominan en la parte alta de los cuerpos sedimentarios (Vera, 2004). Desde el punto de vista geomorfológico, destacan (Gutiérrez, 1994):

- Las altiplanicies de los Páramos calcáreos de edad mio-pliocena (La Alcarria, en sentido estricto).

- Fondos de valles amplios (complejo fluvial del Henares-Bornova ${ }^{3}$ ) o encajados (Badiel, Tajuña y sus tributarios) y sus correspondientes llanuras de inundación (vegas).

- Vertientes y, en Utande, relieves alomados que enlazan mediante laderas, rampas o glacis aquellas altiplanicies con la unidad anterior. En ellas afloran litologías detríticas (arcillas y limos, principalmente), margas y otros niveles carbonatados. En Ambite, además, aparecen sustratos yesíferos en el extremo NE y en algunos otros pequeños focos dispersos (WNW, S y SE).

- Relieves en graderío de terrazas fluviales (ríos Henares y Bornova, en Utande).

Entre las superficies subhorizontales de páramos y vegas se intercala un paisaje tortuoso, pues los valles tienen laderas con pendientes a veces muy abruptas $\left(30-40^{\circ}\right)$, lo que unido a la diversa dirección de los valles da lugar a exposiciones variadas (solanas y umbrías en distinto grado) y, consecuentemente, propicia variaciones microclimáticas de cierta relevancia. Utande presenta laderas más regulares y rectilíneas, pues sus vertientes forman parte de tramos de denudación más reciente de la altiplanicie alcarreña. Sin

${ }^{3}$ Desde un punto de vista geográfico convencional, en este sector, el río Henares se considera como límite de La Alcarria (Ron, 1970; Bellot et al., 1979; García-Abad, 2006). 
embargo, en Ambite al haber sufrido procesos de vertiente más dilatados en el tiempo (deslizamientos, coluviones, etc.), dentro del tramo medio de un valle de mayor cuenca y antigüedad (río Tajuña), tiene laderas más retocadas y complejas.

Debido a los sustratos geológicos dominantes, los suelos son eminentemente de naturaleza básica, pero se dan las siguientes excepciones:

- En Utande, los extremos NW (complejo fluvial del Henares-Bornova) y el WNW (Casas de Tejer) pierden gradualmente la geoquímica carbonatada y aparecen suelos ácidos, debido a la presencia de una facies de antiguos abanicos aluviales del Mioceno Medio que, en su tramo basal (vertiente baja), posee gravas y arenas de mineralogía cuarcito-pizarrosa dominante (Portero et al., 1990). En este pequeño sector, se encuentran como dominantes taxones acidófilos o indiferentes edáficos ${ }^{4}$. Como contrapartida, se observa desde la simple ausencia a una importante minoración de la presencia de los taxones más estrictamente basófilos.

- En ambas cuadrículas, aparecen algunos isleos en los páramos, donde la disolución de calizas deja acumulaciones de terra rossa y con suelos lavados de bases en los horizontes superficiales. Ello permite la implantación esporádica de taxones acidófilos.

En la bibliografía, existen antecedentes sobre estudios florísticos y de vegetación en el área comprendida en estos recintos cartográficos. Pero se trata de estudios con poco detalle espacial que engloban total o parcialmente ambos espacios, ya que se efectuaron para ámbitos geográficos más amplios (Ron, 1970; Izco, 1972; Costa, 1974; Bellot et al., 1979; De la Cruz, 1994; Varela, 1996 y Bartolomé et al., 2002), entre otros estudios. La situación de las dos cuadrículas en diferentes ámbitos biogeográficos y bioclimáticos determina la presencia de elementos florísticos diferenciales que ya fueron denunciados de manera general por Izco (1983).

En ambos recintos, encinares (Quercus ilex subsp. ballota) y quejigares (Quercus faginea subsp. faginea) constituyen las cabezas de serie de la vegetación potencial. En general y aunque de una manera no del todo ajustada por matices microclimáticos y edáficos, los primeros ocuparían los sectores mesomediterráneos, mientras que los segundos se implantarían en los supramedi-

\footnotetext{
${ }^{4}$ Constituye una introgresión del sector "Guadarrámico" (provincia "Mediterránea Ibérica Occidental"), pues aparecen jarales, jaral-romerales y jaral-retamares de la alianza fitosociológica Cistion laurifolii.
} 
terráneos. Además, por razones dinámicas, esta pauta puede verse alterada e, incluso, pueden encontrarse algunos rodales de bosques mixtos. La serie de degradación dominante de ambos tipos de bosques consiste en coscojares y matorrales basófilos xéricos (salviar-tomillares, aliagares, romerales y algunos pocos aljezares de gipsófitos). En ambientes resguardados y menos xéricos, aparecen espinar-rosaledas. En las riberas de los valles y, puntualmente, en algunos barrancos, se implantan modestos bosques ripícolas, normalmente bastante desdibujados, con olmos, chopos, sauces, fresnos y tarayes. Existen, por último, áreas repobladas de pinar (sobre todo en Utande) y chopera.

\section{Factores del medio humano}

Ambas áreas han soportado una actividad agrícola y ganadera secular, con paso de la Cañada Real de Andalucía a Soria en diferentes tramos. En la cuadrícula de Utande, la economía actual es fundamentalmente agrícola, seguida por el uso cinegético y el forestal más extensivo. Dominan los cultivos de secano (cereales y girasol) en cuanto a extensión, que se ciñen sobre todo a los terrenos llanos (páramos, llanuras de inundación y cimeras de terrazas y lomas), y los terrenos de poca pendiente de los tramos bajos de vertientes. En la altiplanicie del páramo son evidentes las consecuencias de la concentración parcelaria acontecida en el último tercio del $\mathrm{S}$. xx, con algunas raras excepciones. Entre los cultivos leñosos, destacan sobremanera los olivares, que todavía suelen labrarse bastante. Son pocas las vides que hoy en día se aprovechan, quedando otras como vestigio de antiguos labrantíos. En huertas de vega y riberas se cultivan frutales, estando ya casi todas las huertas de ladera abandonadas. La ganadería ovi-caprina tiene muy poca importancia hoy en día, aunque tuvo un lugar destacado en décadas y, sobre todo, siglos pasados. Apenas se vieron en la primera década del S. XXI algunos rebaños en el Valle de Valdeiruega y la presencia de un enclave de ganadería estabulada en Villanueva de Argecilla.

En las últimas cinco décadas, se ha experimentado un fuerte descenso demográfico por éxodo rural en casi todos los municipios ${ }^{5}$, con el consiguiente envejecimiento de la población ${ }^{6}$ y abandono paulatino de las actividades agra-

${ }^{5}$ Según datos del I.N.E. se puede cifrar los habitantes en 5.125, 4.325 y 4.283 (censos de 1860, 1910 y 1950, respectivamente), pasándose a tan sólo 763, en 2001, y 798, en 2011.

${ }^{6}$ En los municipios contabilizados anteriormente, la media de edad correspondía en el Censo de 2001 a 56,8 años -la media de España era de 39,5- (I.N.E.). 
rias tradicionales. Esta recesión ha repercutido en la implantación y dinámica vegetal espontáneas que hoy puede observarse, sobre todo en las laderas, con procesos de regeneración natural. Sin embargo, otras actuaciones humanas como el acondicionamiento rural del cauce y de la vega del río Badiel y repoblación de coníferas (Pinus halepensis y P. nigra, fundamentalmente) han afectado con procesos inversos de especial antropización paisajística. En el extremo NW de la cuadrícula de Utande, además, se desarrolla una actividad agrícola intensiva con implantación de riego artificial para el cultivo de maíz, en la vega y terrazas. En la confluencia del Bornova-Henares se mantienen restos de un área extractiva de áridos ya abandonada. Igualmente, existen otras similares que han sido posteriormente reutilizadas como zona de vertido no controlado.

En la cuadrícula de Ambite se repiten, en general, las principales pautas de usos rurales del suelo y morfología agraria referidas para Utande. Pero, hay diferencias. El cuadrante SE de Ambite mantiene todavía una mayor fragmentación parcelaria, sin haber apenas sido alterada por procesos de concentración. Agrícolamente destaca el importante sector vitivinícola presente básicamente en el cuadrante SE, en donde los suelos arcillosos sobre tierras elevadas dan carácter a los Vinos de una Denominación de Origen propia (Mondéjar). Igualmente, el peso de olivares es mayor que en Utande, pues además de en las laderas (donde la mayor parte están abandonados), se implantaron también en las superficies cimeras de páramo y vertientes adosadas (cuadrantes meridionales), donde perdura bastante su labranza. Se repite una pauta hortícola similar a la de Utande. La actividad ganadera pasada y actual tiene un sello también parecido. Destaca la presencia nominal de una Mancomunidad de pastos en el Despoblado de Fuentespino (municipio de Almoguera), pero hoy su uso fundamental es cinegético.

Otro rasgo diferencial respecto a Utande es el demográfico, pues el peso poblacional ha aumentado notablemente desde mediados del S. xIx hasta la actualidad $^{7}$. La causa fundamental ha sido la incidencia de las urbanizaciones de segunda residencia construidas en los últimos cuarenta años cerca de los cascos antiguos (figura 1). Pese a que este crecimiento demográfico supone una mayor presión para el territorio, ello no ha redundado en una mayor explotación del terrazgo agrícola ni de otras actividades rurales, pues esas urba-

7 Según datos del I.N.E. se puede cifrar los habitantes en 5.753, 6.568, 6.901, 9.303 y 13.617 (censos de 1860, 1910, 1950, 2001 y 2011, respectivamente). Pero, el fuerte aumento de la última década se debe al empadronamiento de residentes de las urbanizaciones, según los casos, antes que a la dinámica natural. 
nizaciones y pueblos se han convertido en cierta medida en residencias dormitorio de los núcleos de mayor vigor económico de la comarca (Corredor del Henares, Arganda, la misma capital madrileña, etc). Por tanto, en los «montes» las dinámicas de regeneración ambiental son relativamente parangonables a las señaladas para Utande.

\section{Método}

Se aplica la Metodología de Índices de Ocupación de la Flora explicada en el referido artículo previo (García-Abad, 2015). A ella deben asociarse las siguientes ampliaciones técnico-metodológicas.

\section{Cartografía corológica}

Se sigue el planteamiento establecido por Panareda et al. (1997) de representar mapas corológicos en tres resoluciones diferentes (1, 4 y $\left.25 \mathrm{~km}^{2}\right)$. En las figuras, estos mapas se reproducen manteniendo las proporciones decrecientes propias de cada resolución. En una cuarta representación se añade el resultado conjunto de la cuadrícula de $100 \mathrm{~km}^{2}$ (valor del IOP), aplicable en un eventual mapa sintético subregional.

Con objeto de formalizar la representación de estos mapas corológicos, se establecen tantos sistemas de categorías agregadas de Abundancia Relativa (AR), como resoluciones cartográficas vayan a emplearse. Se aplican dos criterios: a) la nueva categoría agregada de AR se basa en el sumatorio de las AR de las unidades básicas, a modo de IOP para ese nuevo recinto territorial regular; y b) por cada nivel de agregación debe aumentarse al menos en uno el número de categorías respecto al nivel inmediatamente anterior de mayor resolución, con objeto de que la ampliación de la casuística tenga expresión cartográfica. La tabla 1 recoge el sistema de umbrales de valores establecido para este artículo. Es provisional y, por tanto, está abierto a posibles modificaciones y adaptaciones, dependiendo de la aplicación de criterios diferentes. 
TABLA 1

\section{CATEGORÍAS DE ABUNDANCIA RELATIVA EN PLANTAS PVR Y UMBRALES DE VALORES EN LOS AGREGADOS DE LAS DIFERENTES RESOLUCIONES}

\begin{tabular}{|c|c|c|c|c|c|}
\hline & $\begin{array}{cc}\text { Tamaño UTM } & \rightarrow \\
\text { Diagnóstico Cualitativo }\end{array}$ & $\begin{array}{l}1 \mathrm{~km}^{2} \\
1 \times 1 \mathrm{~km}\end{array}$ & $\begin{array}{c}4 \mathrm{~km}^{2} \\
2 \times 2 \mathrm{~km}\end{array}$ & $\begin{array}{l}25 \mathrm{~km}^{2} \\
5 \times 5 \mathrm{~km}\end{array}$ & $\begin{array}{r}100 \mathrm{~km}^{2} \\
10 \times 10 \mathrm{~km}\end{array}$ \\
\hline \multirow{5}{*}{$\begin{array}{l}\text { A } \\
\text { B } \\
\text { U } \\
\text { N } \\
\text { D } \\
\text { A } \\
\text { N } \\
\text { C } \\
\text { I } \\
\text { A }\end{array}$} & Localizada Rarísima & \multirow{2}{*}{0,01} & \multirow{2}{*}{$\geq 0,01$} & \multirow{2}{*}{$\geq 0,01$} & $\geq 0,01$ \\
\hline & Localizada Muy Rara & & & & $\geq 0,20$ \\
\hline & Localizada Rara & \multirow{3}{*}{0,10} & \multirow{2}{*}{$\geq 0,12$} & $\geq 0,30$ & $\geq 1,00$ \\
\hline & Localizada Poco Común & & & $\geq 1,00$ & $\geq 2,00$ \\
\hline & Localizada Común & & $\geq 0,40$ & $\geq 2,00$ & $\geq 5,00$ \\
\hline \multirow{4}{*}{$\begin{array}{c}\mathrm{R} \\
\mathrm{E} \\
\mathrm{L} \\
\mathrm{A} \\
\mathrm{T} \\
\mathrm{I} \\
\mathrm{V} \\
\mathrm{A}\end{array}$} & Muy Común (Frecuente) & 0,25 & $\geq 0,80$ & $\geq 5,00$ & $\geq 12,00$ \\
\hline & Abundante & 0,50 & $\geq 1,50$ & $\geq 12,00$ & $\geq 25,00$ \\
\hline & Muy Abundante & \multirow{2}{*}{1,00} & \multirow{2}{*}{$\geq 3,00$} & \multirow{2}{*}{$\geq 25,00$} & $\geq 40,00$ \\
\hline & Abundantísima & & & & $\geq 60,00$ \\
\hline
\end{tabular}

Fuente: Elaboración propia.

NOTAS:

- Los valores de la columna "l km²" corresponden a las cinco categorías de Abundancia Relativa (AR) inicialmente contempladas por la Metodología de Índices de Ocupación de la Flora.

- En el resto de columnas, los valores son agregados obtenidos por simple suma de las AR de las cuadrículas de $1 \mathrm{~km}^{2}$ fusionadas en los nuevos recintos cartográficos de menor resolución $\left(4,25\right.$ y $\left.100 \mathrm{~km}^{2}\right)$. Se asimilan, por tanto, al valor del Índice de Ocupación de la Planta (IOP) resultante en ellos.

- La nomenclatura de los Diagnósticos Cualitativos puede emplearse a partir de ahora para denominar las diferentes categorías de Abundancia Relativa (AR) en cualquier resolución. Ejemplo (caso de cuadrículas de $2 \times 2 \mathrm{~km}$ ):

- Localizada rarísima a muy rara: valores de 0,01 a 0,11 .

- Localizada rara a poco común: 0,12 a 0,39.

- Localizada común: 0,40 a 0,79 .

- Muy común: 0,80 a 1,49 .

- Abundante: 1,50 a 2,99 .

- Muy abundante a abundantísima: 3,00 ó más. 
Cada figura representa los mapas con la distribución de la presencia y abundancia de dos plantas, en las dos cuadrículas y con las cuatro resoluciones referidas. Los mapas con resolución de $1 \mathrm{~km}^{2}$ tienen una cartela en la parte superior donde se identifica la cuadrícula de $100 \mathrm{~km}^{2}$ y se indican tres referencias cuantitativas: número de orden de la planta en esa cuadrícula según el valor de IOP, este valor y la frecuencia (número de recintos donde está presente). Aparecen con rayado las dos cuadrículas de Ambite que no pudieron ser inventariadas. Los mapas de $4 \mathrm{~km}^{2}$ tienen una cartela en la esquina superior derecha que indica la frecuencia. En ellos también se advierte con rayado que el dato de AR es incompleto. Por razones de espacio y para evitar exceso de signos convencionales, cada figura incluye en la parte inferior únicamente la leyenda de los mapas de $1 \mathrm{~km}^{2}$. Las categorías de las otras resoluciones se deducen fácilmente de la tabla 1 y de comentarios incluidos en el apartado "Resultados".

\section{Valoraciones fitogeográficas}

Para cada planta analizada se emplea un método cualitativo de valoración fitogeográfica que se basa en: a) una muy variada documentación bibliográfica previa en la que, entre otras referencias, se consideran las apetencias ecológicas de las plantas que se deducen de los numerosos estudios fitosociológicos realizados en España (Rivas-Martínez et al., 2002); b) constataciones derivadas del análisis de los factores geográficos antes expuestos; c) anotaciones geo-ecológicas concretas tomadas mediante observación directa en campo; y d) algunos testimonios recabados de paisanos. Los resultados se expresan en forma de comentarios fitogeográficos específicos.

En este análisis fitogeográfico se establece que, para la escala local empleada, la ausencia de avistamientos de una planta en áreas de $3 \times 3 \mathrm{~km}$ ó $6 \times 2 \mathrm{~km}$ es lo suficientemente relevante, por la compacidad y extensión territorial que conllevan, como para considerar tales disyunciones como límites locales de distribución.

\section{RESULTADOS}

\section{Caracterización general}

Se muestran solo plantas pertenecientes al contingente PVR (permanentemente visibles y reconocibles) establecido en García-Abad (2015). En concreto, se ofrece una primera muestra de distribuciones geográficas correspondiente a 
las doce plantas de mayor ocupación en Ambite y Utande, pues alcanzan los IOP más elevados conjuntos cuando se suman los de ambas cuadrículas. Se exponen en orden de mayor a menor valor sumatorio resultante. En todos los casos, se trata de plantas de distribución mediterránea o late-mediterránea, ampliamente conocidas y extendidas en España, y en tres casos son endemismos ibérico-baleares (tomillo aceitunero, quejigo y salvia).

\section{Distribución de los taxones mayoritarios y comentarios fitogeográficos}

$1^{\circ}$ ) Genista scorpius (L.) DC. (Aliaga o aulaga, figura 2a). Pese a ocupar el segundo lugar en Utande y el cuarto en Ambite, por la suma de sus dos IOP es la planta que lidera el conjunto de las 198 cuadrículas inventariadas. Su frecuencia también es de las más elevadas. Esta posición preeminente es alcanzada por la gran abundancia con que se presenta en los matorrales xéricos basófilos resultantes de la degradación del bosque. Da lugar a frecuentes formaciones propias de aliagar, siendo más dominantes y densas cuanto menor es la incidencia de la insolación, por lo que son comunes en tramos cóncavos, umbrosos y algo resguardados de laderas. Es habitual encontrarla también en monte bajo y, aunque baja su abundancia considerablemente en el interior de bosques, es normal verla en los sotobosques (incluidos los de ribera). La unidad geográfica donde se implanta más extensamente es la de laderas y demás vertientes. Pero está presente en todas las unidades. Su presencia solo es de minoritaria a nula en aquellos sectores que están extensa e intensamente cultivados.

Los mapas de $1 \mathrm{~km}^{2}$ reflejan bien las referidas preferencias por vertientes, frente a páramos y fondos de valle; así como por los sectores menos expuestos a la insolación. No deja de presentarse en las áreas de sustrato ácido del NW de Utande, aunque disminuyendo bastante su abundancia. Este hecho se refleja muy bien en el mapa de $4 \mathrm{~km}^{2}$, donde la abundancia oscila entre "Localizada rarísima a muy rara" y "Abundante". Esta última categoría, sin embargo, no es alcanzada por ningún recinto en Ambite. La diferencia de más de 10 puntos en los valores de IOP entre Utande y Ambite queda bien reflejada en los mapas de $25 \mathrm{~km}^{2}$ (en Utande, los cuatro recintos tienen la categoría "Muy común"; pero solo uno en Ambite, estando el resto en "Localizada común"). Globalmente (cuadrícula de $100 \mathrm{~km}^{2}$ ), alcanza la categoría "Abundante", en Utande; pero, en Ambite, se queda en "Muy común".

De lo expuesto, puede deducirse una mayor apetencia de la aliaga por el piso supramediterráneo y, por tanto, podría sugerirse como hipótesis que, dinámicamente, presenta más relevancia en la serie del quejigar que en la del encinar. 

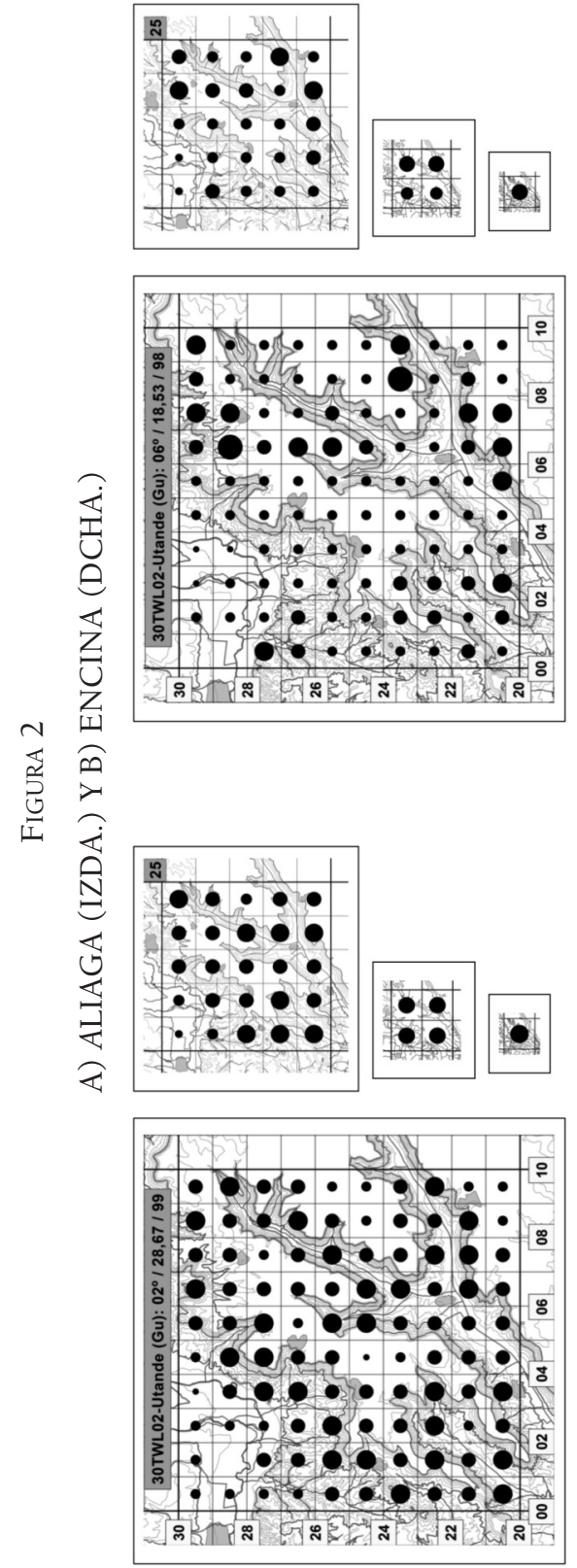

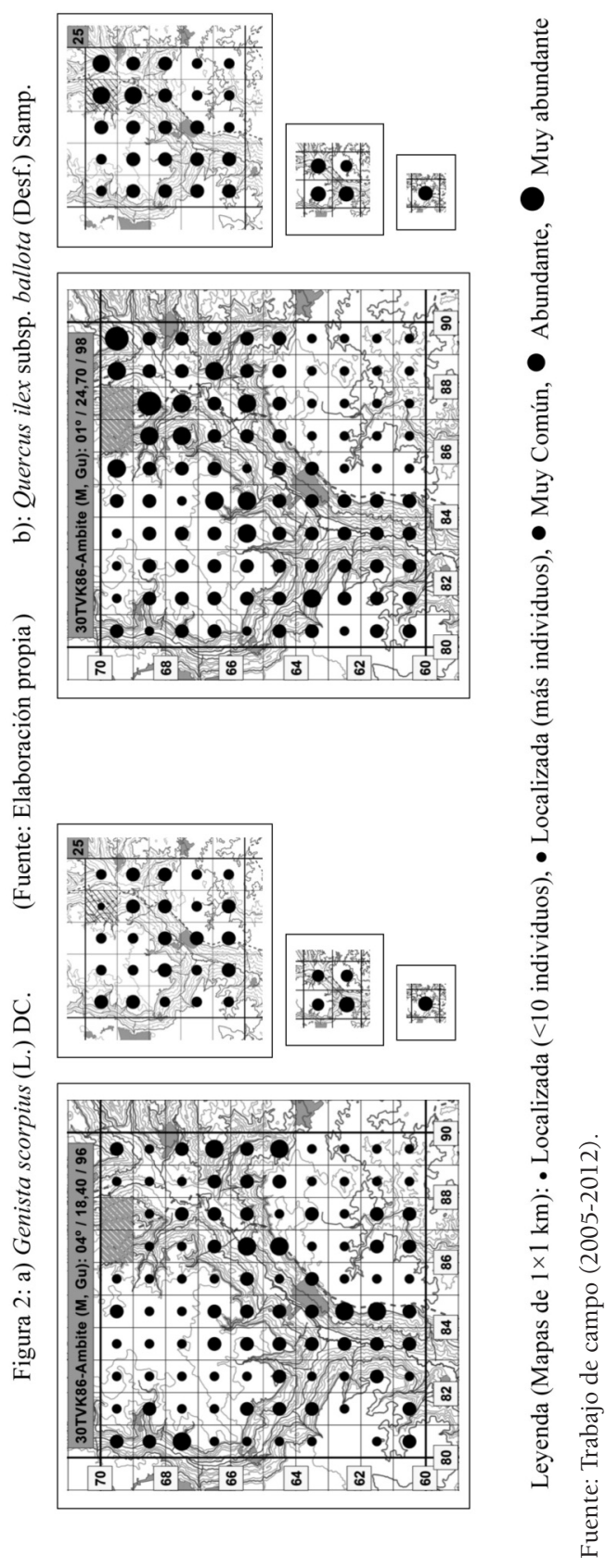

Estudios Geográficos, Vol. LXXVII, 280, pp. 81-113, enero-junio 2016 ISSN: 0014-1496, eISSN: 1988-8546, doi: 10.3989/estgeogr.201604 
$2^{\circ}$ ) Quercus ilex subsp. ballota (Desf.) Samp. (Encina, figura 2b). Cuando se suman los dos IOP, los valores de la encina se encuentran muy próximos a los de la aliaga, pero su peso está invertido pues son sobradamente mayores en Ambite respecto a Utande. Continúa la pauta de una ocupación prácticamente total del territorio, pues su frecuencia también es de las más elevadas. Son bastantes los bosques quercíneos que se mantienen en ambos territorios, pero en Utande los encinares están bastante repartidos con quejigares, mientras que son claramente mayoritarios respecto a éstos en Ambite (Véase figura 6b). La encina se presenta también en formaciones de encinar-quejigares, quejigares con encina, y monte bajo, además de ocupar con menor abundancia matorrales y aparecer en pequeños rodales o como individuos aislados en áreas de cultivo (parcelas adehesadas), setos, lindes, etc. Se implanta extensamente en laderas y vertientes, tanto solanas como umbrosas, pero también ocupa importantes áreas en el páramo no cultivado. Ocupa también lomas y, con mucha menor abundancia, vertientes de terraza (Utande). Con rarísimas excepciones, falta en los fondos de valle y vegas. En Ambite, se ha respetado relativamente bastante su presencia en los páramos cultivados de los cuadrantes NW y SW, pero muy poco en el SE, donde la concurrencia de viñedos, olivares y cereales de secano han dejado menos opciones a la encina. No deja de presentarse en áreas de sustrato ácido (Utande). Sólo falta en cuadrículas ampliamente ocupadas por maizales y choperas, en la vega del Henares.

Los mapas de $1 \mathrm{~km}^{2}$ reflejan bien los contrastes referidos, destacando cómo en Ambite es más palpable la continuidad geográfica de más abundancia respecto a Utande, donde se observan discontinuidades entre algunos focos aislados de mayor ocupación (con categorías de "Muy común" y "Abundante"). Los mapas de $4 \mathrm{~km}^{2}$ también reflejan en general esas variaciones. En ellos, se marca bien la menor presencia en los cinco recintos del páramo del SE de Ambite. La diferencia en torno a 6 puntos en el IOP entre Utande y Ambite queda reflejada en los mapas de $25 \mathrm{~km}^{2}$ (en Ambite hay tres recintos con categoría "Muy Común", pero dos en Utande). Globalmente, en ambas cuadrículas la encina alcanza la categoría "Muy común".

Pese a que la dinámica impuesta por la acción humana podría transgredir el sentido de los cómputos del IOP, en todo caso puede deducirse una mayor decantación bioclimática de la encina por el piso mesomediterráneo.

$3^{\circ}$ ) Thymus vulgaris L. subsp. vulgaris (Tomillo común, figura 3a). Los valores conjuntos del IOP y su reparto en cada cuadrícula son muy similares a los de la encina, pero la distribución de la abundancia difiere. Tanto en Ambite como en Utande, con excepción de unos pocos recintos, no coinciden las 

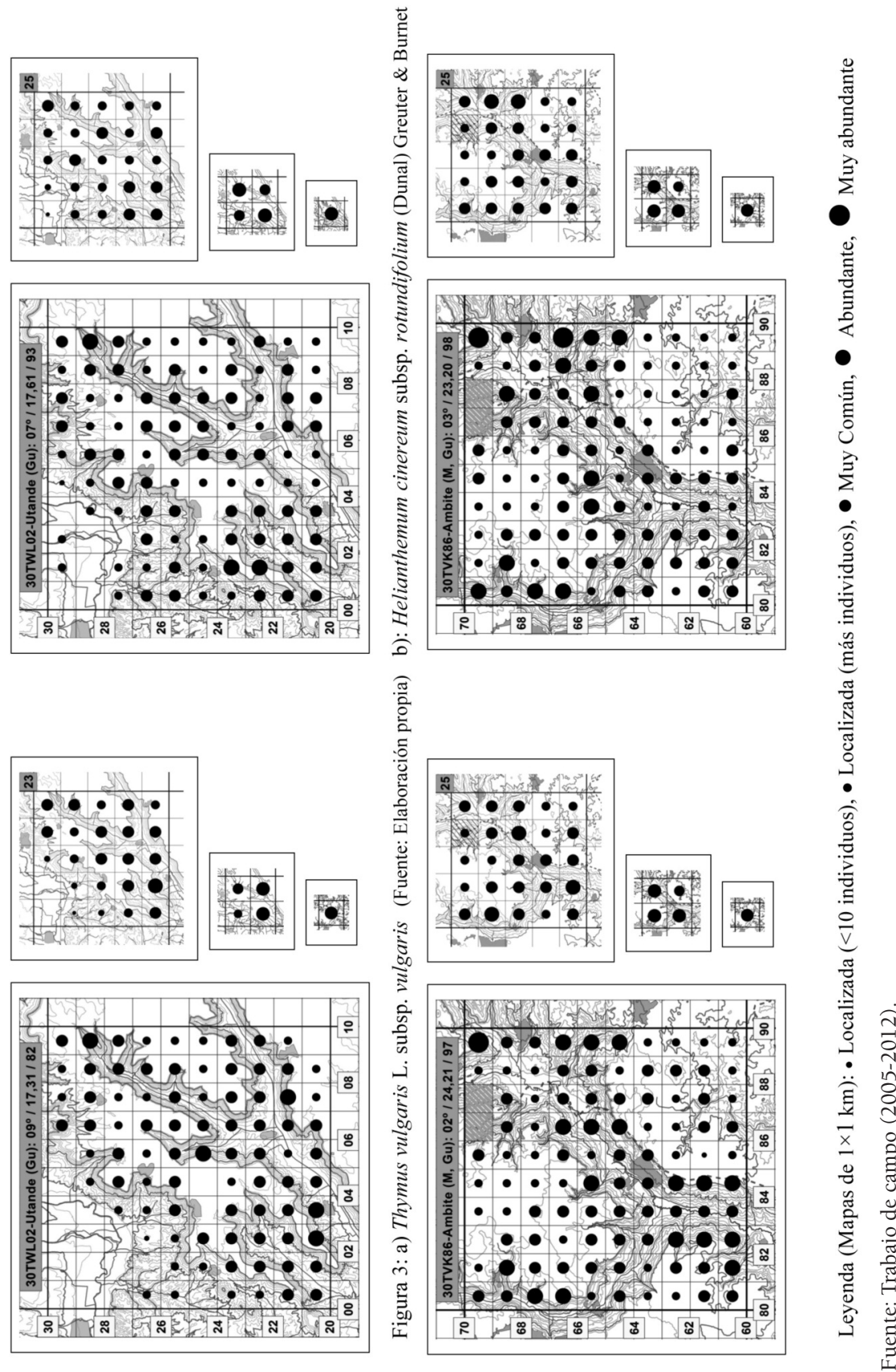

Estudios Geográficos, Vol. LXXVII, 280, pp. 81-113, enero-junio 2016 ISSN: 0014-1496, eISSN: 1988-8546, doi: 10.3989/estgeogr.201604 
cuadrículas de mayor abundancia entre ambas especies; dicho de otro modo, hay cierta complementariedad. Ello muestra, de entrada, los diferentes ambientes en que medran; pues este tomillo ocupa sobre todo tomillares, además de matorrales xéricos basófilos y monte bajo, y mucho menos bosques. En el resto de rasgos, el tomillo común coincide bastante con la aliaga, aunque difiere en que su abundancia está invertida entre Ambite, donde está mucho más extendida, y Utande. Además, el tomillo común desaparece en los sustratos ácidos del NW de Utande, complejo fluvial Henares-Bornova, algunas últimas laderas del páramo y algunas cuadrículas del páramo más ampliamente cultivadas. Ello configura un límite local de distribución, unido a un descenso en la frecuencia de aparición en esta última cuadrícula. Con raras excepciones, falta en los fondos de valle y vegas.

Los mapas de $4 \mathrm{~km}^{2}$ reflejan bien en Utande una transición gradual entre la ausencia (con límite neto) y una gran ocupación en el interior alcarreño (mitad oriental de la cuadrícula), donde en un recinto alcanza incluso la categoría "Abundante". En Ambite expresan la continuidad de una importante abundancia solo rota en algunos sectores del páramo cultivado (categorías desde "Localizada común" a "Abundante"). La resolución de $25 \mathrm{~km}^{2}$ no permite representar el límite de distribución de Utande, pero sí evidencia una minoración de la abundancia en el cuadrante NW y, desde luego, la menor implantación en Utande respecto a Ambite. Sin embargo, globalmente (100 $\mathrm{km}^{2}$ ) no se aprecian las diferencias entre las dos cuadrículas, presentándose ambas con la categoría "Muy común".

De lo expuesto, parece haber un mayor vínculo del tomillo común con el piso mesomediterráneo y con la serie del encinar.

$\left.4^{\circ}\right)$ Helianthemum cinereum subsp. rotundifolium (Dunal) Greuter \& Burnet (Ge del campo, figura 3b). Este diminuto caméfito habita en matorrales, monte bajo, coscojares y claros de encinares y quejigares. Presenta unas pautas de implantación territorial prácticamente iguales a las del tomillo común en ambas cuadrículas, por la gran proximidad autoecológica de ambos taxones. La única diferencia relevante es que, en el NW de Utande, no desaparece del todo, pese a los sustratos ácidos de Casas de Tejer y usos agrícolas intensivos del Valle del Henares. Una cierta menor restricción autoecológica hace que su distribución sea algo más amplia que la del tomillo común.

Fuera de esto, los mapas muestran únicamente pequeños matices de abundancia entre ambos taxones, que se cifran en una implantación solo muy ligeramente menor del ge del campo, pese a ser algo más frecuente que el tomillo. En Ambite ocupa más espacio y tiene una mayor implantación en la mitad su- 
perior de la cuadrícula y, sobre todo, en el cuadrante NE. Respecto al tomillo común, tiene una menor implantación en la mitad inferior. Respecto a la aliaga, se constata una igualdad en el IOP, pero con ligeros matices. La resolución de $4 \mathrm{~km}^{2}$ alcanza para captar con justa nitidez la menor ocupación en Utande de su extremo NW (aparecen recintos con categorías "Localizada rarísima a muy rara" y "Localizada rara a poco común"). Igualmente, permite apreciar con suficiencia la mayor ocupación en Ambite (categorías "Localizada común" a "Abundante") respecto a Utande. Sin embargo, los mapas de $25 \mathrm{~km}^{2}$ apenas evidencian este último hecho. Dados los IOP tan próximos, tampoco revelan diferencia alguna en ambas cuadrículas entre el tomillo común y el ge del campo. Globalmente, en un mapa subregional de $100 \mathrm{~km}^{2}$ se mantendría la misma categoría ("Muy común") en todos los casos.

$5^{\circ}$ ) Brachypodium retusum (Pers.) P. Beauv. (Lastón, figura 4a). Llama la atención su ocupación tan dispar en ambas cuadrículas, siendo la planta que curiosamente tiene el IOP más alto de los detectados hasta ahora: lidera Utande con la categoría "Abundante", pero en Ambite apenas es "Localizada poco común". Es propio de pastizales vivaces xéricos basófilos. Da lugar en Utande a formaciones propias de lastonar y sus mezclas con sufrútices (lastonar-salviares, lastonar-tomillares, etc.). También aparece con profusión en matorrales. Igualmente, es común en bastantes sectores de encinar, monte bajo y quejigares, incluso cuando los bosques están relativamente cerrados; además de otras formaciones (espinosas, etc.). Su mayor implantación se da en laderas y demás vertientes, pero es habitual encontrarla también en áreas de páramo que mantienen formaciones vegetales espontáneas, lomas, barrancos, cuestas de terraza y otras unidades. Cabe advertir en Utande la muy similar distribución geográfica que tiene su abundancia respecto a la aliaga, con la que comparte espacios en diferentes combinaciones de dominancia. También está presente en ámbitos ácidos, por lo que en conjunto su frecuencia es extremadamente amplia y tan sólo falta en el complejo fluvial Henares-Bornova. Sin embargo, en Ambite apenas hay lastonares (pocos y en muy pequeños rodales) y prácticamente deja de participar en otras formaciones. Su frecuencia es media-baja y su abundancia aún mucho más modesta, siendo muy difícil de avistar.

Mientras los mapas de $4 \mathrm{~km}^{2}$ apenas marcan en Utande una menor abundancia en el extremo NNW y, sobre todo, una continuidad de su gran abundancia solo matizada ligeramente allí donde se concentran áreas cultivadas; en Ambite evidencian no sólo un amplio límite local de distribución en el cuadrante NE, sino una ocupación modestísima generalizada. La resolución de 25 


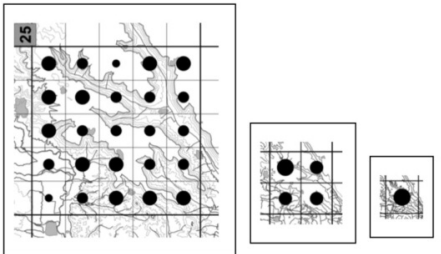$$
\text { ङำ }
$$

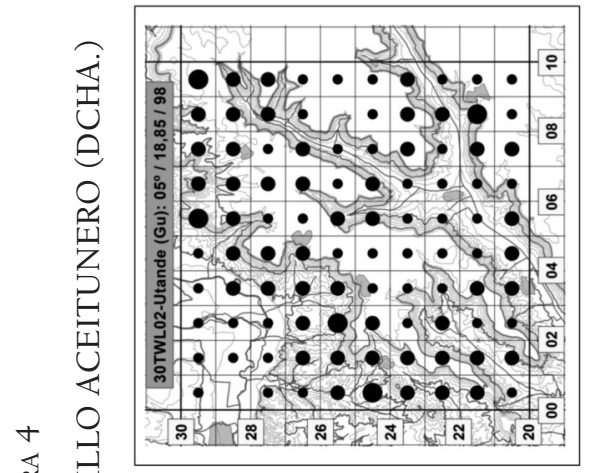

志

2

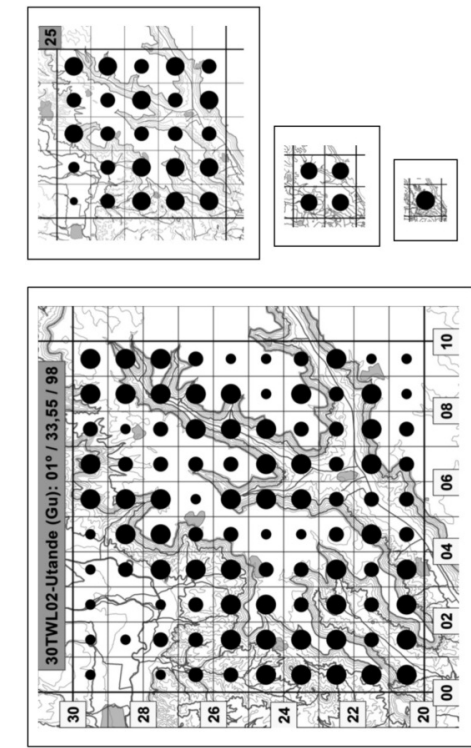

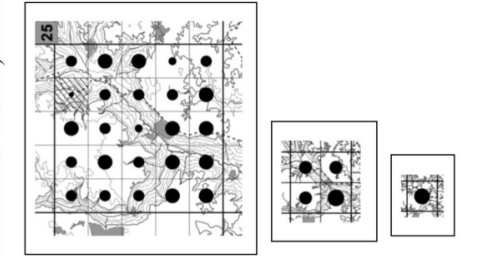

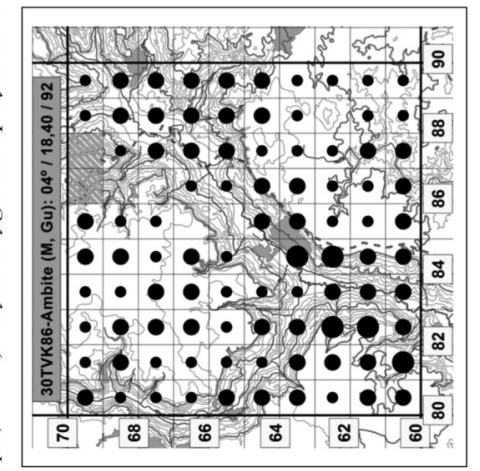

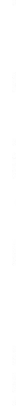

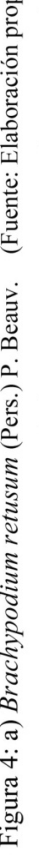


$\mathrm{km}^{2}$, sin embargo, no pone de manifiesto el referido límite local en Ambite, aunque sí una bajísima presencia en su mitad oriental.

Las diferencias entre Utande y Ambite no se deben tanto a razones ecológicas o bioclimáticas, sino más a la diferente continuidad recurrente de incendios para favorecer un extenso aprovechamiento ganadero en la primera cuadrícula. Éste ha sido más persistente y prolongado en el tiempo en Utande $^{8}$, cuyo carácter en el uso ha sido concomitante con el potencial productivo y ritmo fenológico propios de este taxón, pese a que su valor pascícola no sea precisamente elevado: son pastos duros (Buendía, 2000). El ganado consume sobre todo la espiga, lo que ha favorecido su reproducción vegetativa por rizomas, propiciando la densificación de sus céspedes y el alto cubrimiento del suelo. En la Alta Alcarria, donde las condiciones bioclimáticas son menos halagüeñas para la agricultura respecto a la Baja Alcarria y, además, la morfogénesis de laderas se encuentra en fase de modelado más joven, con mayores pendientes y pedregosidad, la vocación histórica del territorio ha sido principalmente pecuaria. Los pastores, con más libertad de acción, han fomentado las quemas para controlar los rebrotes de plantas leñosas y, así, favorecer la entrada de herbáceas. Esta dinámica, junto al especial papel enriquecedor que tiene la ceniza para esta planta, fue evidenciada por De Luis et al. (2004). Destaca, además, el importante papel que juega como estabilizadora de laderas (González, 1997) y, por tanto, en términos de Meaza y Cuesta (2010), el relevante valor fitoagente que posee por sus funciones fitoactivas geomorfológica y edáfica. La continuidad de sus céspedes genera un manto rizomatoso subalveolar que retiene los primeros centímentros de suelo y, aunque en equilibrio precario, favorece la edafogénesis. En Ambite, la particular configuración de su distribución parece responder a procesos similares, aunque sólo anecdóticamente, en torno a los ramales pecuarios que cruzan de $\mathrm{N} \mathrm{a}$ S la cuadrícula.

$\left.6^{\circ}\right)$ Thymus zygis subsp. sylvestris (Hoffmanns. \& Link) Brot. \& Cout. (Tomillo aceitunero, figura 4b). Este otro tomillo también está ampliamente implantado en ambas cuadrículas. Los hábitats y unidades geográficas donde se presenta coinciden bastante con los de su congénere, la aliaga y el ge del campo, perdiendo abundancia en páramos y fondos de valle debido a la extensión de los cultivos. La única diferencia notable frente al tomillo común es que habita con normalidad en los terrenos ácidos de Casas de Tejer, por lo que

\footnotetext{
${ }^{8}$ Hay una secular tradición pecuaria en la comarca, pues hasta los años sesenta del S. Xx en Jadraque hubo una feria de ganado desde época medieval. 
en Utande presenta mayor frecuencia y una ligera mayor ocupación. Mantiene unas diferencias similares respecto al ge del campo en la cuadrícula altoalcarreña. En Ambite, por contra, su implantación es notoriamente menor que los dos últimos caméfitos referidos, tanto en abundancia como en frecuencia, llamando la atención su no avistamiento en un sector lineal continuo del borde del páramo. En las dos cuadrículas los IOP son prácticamente iguales, mostrando una muy ligera frecuencia menor en Ambite.

Los mapas de $4 \mathrm{~km}^{2}, 25 \mathrm{~km}^{2}$ y $100 \mathrm{~km}^{2}$, evidentemente, no muestran diferencias entre ambas cuadrículas. Tan solo cabe referir la disminución ocasional de su ocupación. Respecto al tomillo común y ge del campo, en Utande, aquellos mapas solo registran de manera muy leve diferencias de distribución de la ocupación. En Ambite, sin embargo, salvo el mapa global de 100 km², las otras resoluciones sí marcan suficientemente la menor ocupación del tomillo aceitunero.

$7^{\circ}$ ) Lavandula latifolia (L.) Medik. (Espliego, figura 5a). Esta conocida aromática, posee una autoecología similar a los anteriores caméfitos. Pero muestra una reducción significativa de ocupación y frecuencia en Ambite, aunque no así en Utande donde mantiene o supera ligeramente los niveles respecto a los tomillos y ge del campo. Encontramos el espliego en salviar-esplegares, lastonar-salviares, aliagares, tomillares, romerales, así como en monte bajo e, incluso, ya con baja frecuencia, en el interior del bosque quercíneo. Como el tomillo común, desaparece en los ámbitos ácidos de Casas de Tejer, de dominio fluvial y maizales, pero se mantiene en el resto de cuadrículas, incluso en las ampliamente cultivadas del páramo. Presenta unos focos de especial abundancia en las últimas laderas de La Alcarria y mantiene niveles ligeramente menores pero bastante constantes en las del interior alcarreño. Según testimonio de lugareños, en los años cincuenta/sesenta del S. xx, fue recolectado para esencias en el Valle de Valdeiruega por cuadrillas de hasta unas pocas decenas de paisanos, lo que indica los cuidados que debió recibir para su aprovechamiento. En cambio, en Ambite es notoria la ausencia en dos/tres focos de cuadrículas parameras alteradas por el cultivo, pero manteniendo en casi todas las laderas las mismas pautas de ocupación de Utande. En todo caso, la disminución de la ocupación es ya muy notable respecto a los tomillos (sobre todo, el común) y ge del campo.

Los mapas de $4 \mathrm{~km}^{2}$ manifiestan claramente las diferencias de ocupación entre ambas cuadrículas, pero no así los mapas de resolución más grosera. Puede deducirse un gradiente de ocupación decreciente de Norte a Sur en La Alcarria Occidental. 

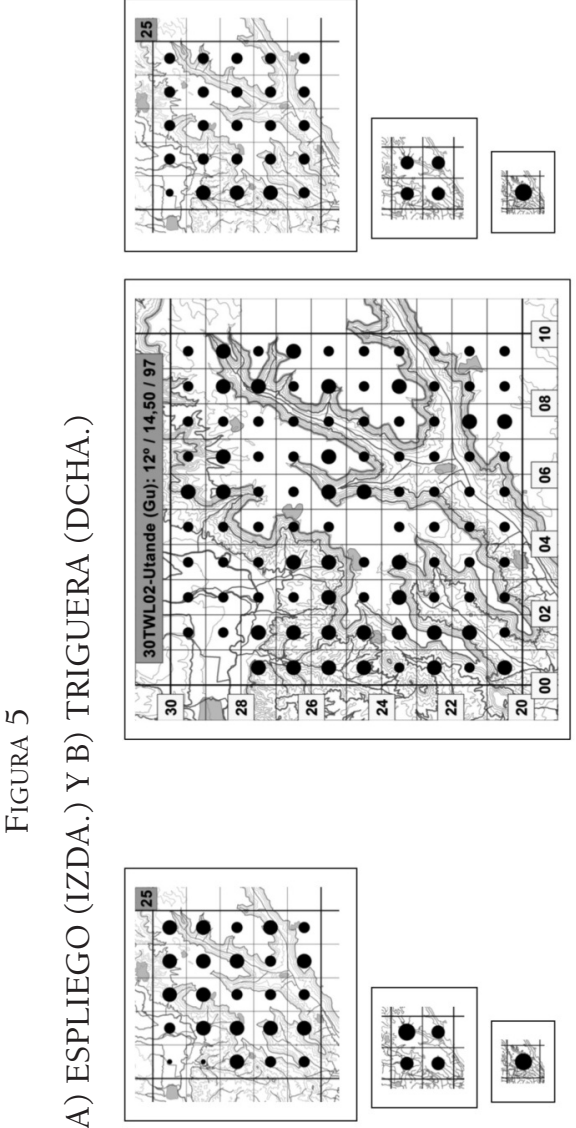

怘

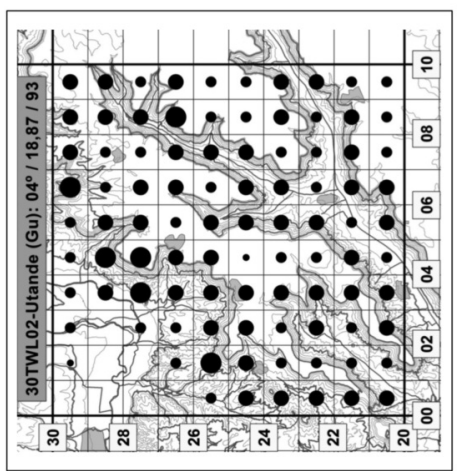

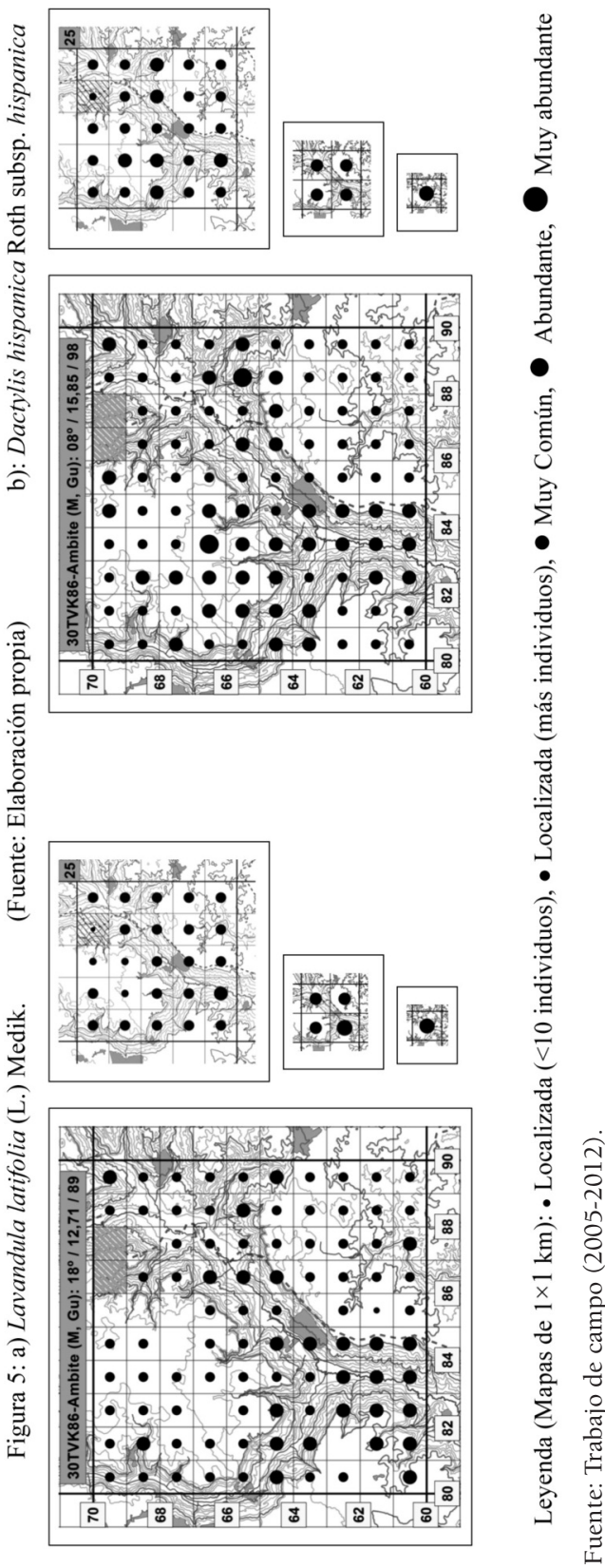

Estudios Geográficos, Vol. LXXVII, 280, pp. 81-113, enero-junio 2016 ISSN: 0014-1496, eISSN: 1988-8546, doi: 10.3989/estgeogr.201604 
$\left.8^{\circ}\right)$ Dactylis hispanica Roth subsp. hispanica (Triguera, figura 5b). Esta herbácea vivaz cuyo hábitat predominante son los pastizales xéricos, ha sido también favorecida por la actividad pecuaria en ambas cuadrículas. Pasto apetecido por el ganado, sobre todo en su etapa de crecimiento (Buendía, 2000), también contribuye a fijar suelo (González, 1997). Es casi indiferente edáfica pues, aunque prefiere los terrenos calizos, medra bien en sustratos ácidos (González, 1997; Buendía, 2000), según se comprueba por mantener también niveles máximos de abundancia en Casas de Tejer. Presenta su mayor ocupación en el extremo occidental de la cuadrícula, coincidiendo con ramales pecuarios secundarios que no alcanzan el páramo, en ámbitos dominados por detríticos que afloran con baja cobertura vegetal. De todas formas, la triguera no falta en matorrales, monte bajo e, incluso, bajo dosel quercíneo, siendo las vertientes nuevamente las unidades de mayor implantación; y no quedando del todo afectada por la extensión de cultivos. En Ambite, tiene un IOP levemente mayor, corroborado por alcanzar la máxima frecuencia posible. Las pautas de ocupación se repiten, destacando la menor abundancia detectada en el cuadrante SE, donde viñas y olivares se unen a las tierras de labor.

Los mapas de $4 \mathrm{~km}^{2}$ delatan claramente en Utande sectores con mayor (W) y menor abundancia (amplios cultivos del NW). Aunque la representación del conjunto $\left(100 \mathrm{~km}^{2}\right)$ no evidencia todavía menor abundancia respecto a los taxones anteriores (salvo el lastón), los mapas de $25 \mathrm{~km}^{2}$ sí expresan ya una menor abundancia (los cuatro recintos tienen la categoría "Localizada común" en ambas cuadrículas).

Aunque con diferencias muy poco reveladoras del IOP, parece que la ligera mayor xericidad de Ambite respecto a Utande podría explicar esa leve mayor presencia en la cuadrícula meridional.

$\left.9^{\circ}\right)$ Rosmarinus officinalis L. (Romero, figura 6a). Es planta propia de matorrales xéricos de sustratos tanto ácidos como básicos (incluso tolera los yesíferos). Se puede encontrar en salviar-esplegares, lastonar-salviares, tomillares, jaral-romerales, romeral-aliagares, quejigar-romerales y, ya menos, en espartales, aliagares, monte bajo, quejigares y encinares. Pero su mayor abundancia la presenta en formaciones propias de romeral, pues al soportar bien biotopos especialmente áridos, soleados o con suelos degradados por erosión (primo-colonizador), recibe en ellos muy poca competencia de otros arbustos. Manifiesta una clara preferencia por la exposición directa del sol (heliófila), razón por la cual es raro encontrarlo en exposiciones de umbría o áreas sin exposición (páramos llanos). Se encuentra sobre todo en laderas de 
solana y tramos en que, por tener más pendiente, la incidencia de la radiación es mayor; o bien en sectores convexos o con resalte que acentúan o se aproximan más a tal exposición (escarpes); así como en los bordes de páramo próximos a esos escarpes y sus pies. En este sentido, se caracteriza por formar manchas discretas (con límites abruptos), instalándose poco en sectores donde las condiciones xéricas menos severas permiten la entrada de otros arbustos, para evitar competir con ellos. En el cuadrante NW de Ambite ocupa con cierta abundancia áreas de páramo bajo (800 a 850 m s.n.m.), con leve exposición solana, con restricciones agrológicas por pedregosidad cubiertas por matorrales y monte bajo. Estas circunstancias difieren en Utande, donde esas «alcarrias» son más llanas y elevadas $(1000 \mathrm{~m})$, por lo que aquí prácticamente no se presenta en páramo. Otro rasgo curioso es la presencia de formaciones mixtas de romeral y quejigar bajo, con dinámica progresiva de éste por regeneración sucesional, en laderas solanas de alta cota (920 a $1000 \mathrm{~m}$ ) que sufrieron procesos erosivos cuando la presión humana fue intensa. En algunos tramos donde el quejigar se ha cerrado, todavía hay bastante romero en el sotobosque. La extensión e intensificación del cultivo incide negativamente en su presencia.

En los mapas se comprueban de manera diáfana estas pautas de distribución en ambas cuadrículas. En Utande hay un amplio límite local de distribución que en Ambite no se alcanza por poco (criterio del epígrafe 2.2.), aunque sí hay focos de ausencia. Ello contrasta con otros cercanos de abundante ocupación. Ésta es incluso máxima en dos cuadrículas de Ambite (Valdealcalá y Monte Herrera). Los mapas de $4 \mathrm{~km}^{2}$ delatan bien tales rupturas en la distribución y los de $25 \mathrm{~km}^{2}$ también presentan recintos con tres diferentes categorías de abundancia: desde la "Muy común" hasta la "Localizada poco común", en ambas cuadrículas.

Este modelo especial de distribución se da en ambas cuadrículas. Pese a faltar en más de dos decenas de recintos de $1 \mathrm{~km}^{2}$, mantiene altos niveles conjuntos de ocupación respecto a otras plantas. La dinámica sucesional debida a transformaciones antrópicas constituye un factor importante en su distribución y abundancia. El ligero mayor IOP obtenido en Ambite, junto a una frecuencia también más elevada, es fruto de una aridez climática más acentuada en esta cuadrícula. 

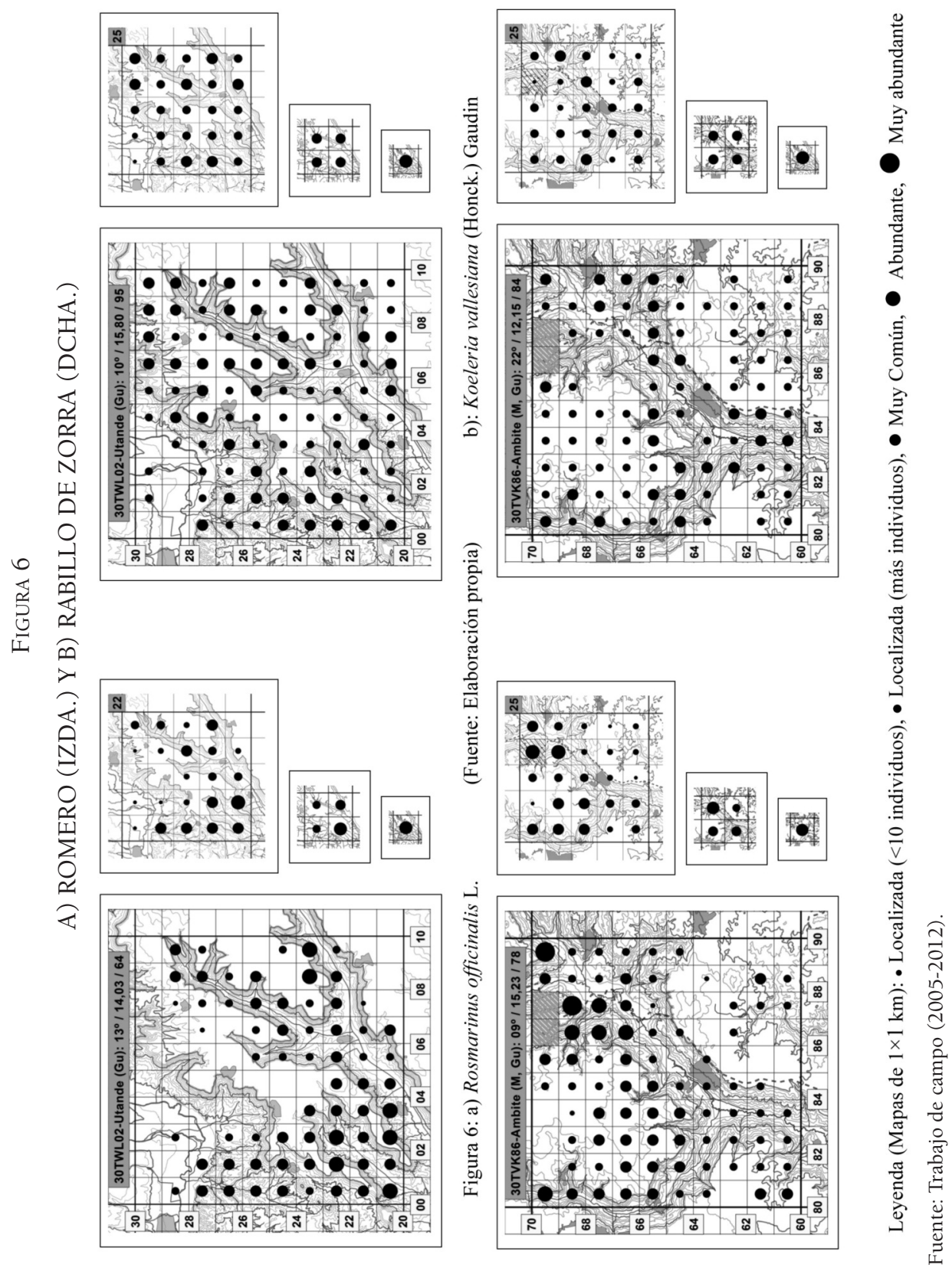

Estudios Geográficos, Vol. LXXVII, 280, pp. 81-113, enero-junio 2016

ISSN: 0014-1496, eISSN: 1988-8546, doi: 10.3989/estgeogr.201604 
$10^{\circ}$ ) Koeleria vallesiana (Honck.) Gaudin (Rabillo de zorra, figura 6b). Esta otra herbácea cespitosa es propia de pastizales dominados por hemicriptófitos y caméfitos de baja talla, basófilos, xéricos y de carácter montano, por lo que en La Alcarria comparte amplios espacios con las otras gramíneas analizadas (lastón y triguera), siendo un taxón que resiste bien el pastoreo (Buendía, 2000), aunque de mediocre interés ganadero (González, 1997). Habita también en matorrales y bosques, sobre todo en vertientes, y es afectada nuevamente por los cultivos de páramo. Tolera los sustratos ácidos de las lomas de Casas de Tejer. En Utande presenta una distribución y abundancia muy parecida a la de la triguera, aunque ligeramente mayor por su carácter submediterráneo, ocupando más espacios que ella en su «interior» alcarreño. Falta en el complejo fluvial Henares-Bornova. El clima algo más térmico hace que en Ambite baje más de 3 puntos en IOP, así como su frecuencia. Unido a este factor, el uso agrícola del territorio contribuye a minorar también su implantación en esta cuadrícula, siendo mayor aún la diferencia respecto a la triguera (casi 5 puntos), más resistente a la aludida termicidad.

Los mapas de $4 \mathrm{~km}^{2}$ muestran en Utande el matiz señalado de una mayor abundancia oriental del rabillo de zorra respecto a la triguera, mientras que en Ambite se observa generalizada su menor implantación, con hasta seis recintos con la categoría "Localizada rara a poco común". La comparación entre ambas cuadrículas muestra también con claridad la ocupación más reducida de la planta en Ambite. Sin embargo, los mapas con resolución más grosera no permiten observar ninguna diferencia entre ambas cuadrículas ("Muy común" en todos los casos).

$11^{\circ}$ ) Quercus faginea Lam. subsp. faginea (Quejigo o Roble, figura 7a). Se presenta fundamentalmente en formaciones propias de quejigar, pero también está presente en encinar-quejigares, encinares con quejigo, monte bajo, quejigar-romerales y como elemento aislado puntual en matorrales, lindes y setos. Laderas, sobre todo umbrosas, páramo, lomas bajas, vertientes de terrazas y vega del Henares, en orden decreciente de ocupación, son las unidades geográficas donde se encuentra. En Utande está presente en casi todas las cuadrículas, pero destaca que en 16 su ocupación sea mínima, concentradas en varios focos del páramo cultivado y del complejo fluvial del NW. Comparada con la encina, se observa una gran igualdad cuantitativa en la ocupación, pero los ámbitos de dominio suelen ser diferentes. El quejigo domina ampliamente el sector occidental, sobre todo en Casas de Tejer en razón de una mejor conservación naturalista por parte del hombre (extenso bosque, gran propiedad, uso cinegético principal). Sin embargo, en las proximidades de Jadraque (N), 
Miralrío, Utande y Valfermoso de las Monjas los usos históricos pecuario y forestal (carboneo) decantaron el favorecimiento antrópico de la encina que, incluso, todavía hoy se presenta como dominante en laderas de umbría. Pese a ello, los tramos bajos de las umbrías de Utande, con más espesor del suelo, mayor capacidad de retención hídrica, junto a otros factores ambientales son más propicios para el quejigo. De hecho, se ha constatado allí una importante regeneración del quejigo que, aun siendo minoritario todavía, presenta una dinámica progresiva. Si se mantuviera la bajísima presión agraria, es muy probable que en décadas venideras el quejigo desplace más y más a la encina, tal y como ya está empezando a ocurrir. Igualmente, el abandono hace varias décadas del uso pecuario ha permitido al quejigo ganar importantes espacios en las muy acentuadas umbrías de la cabecera del Valle de Valdeiruega.

En Ambite, la situación difiere bastante, pues los valores del IOP son menos de la mitad respecto a Utande. La frecuencia también está bastante alejada. Aparte de esta constatación, el mapa evidencia también una presencia ridícula en 25 cuadrículas. Es una pauta, pues, que se repite en ambos territorios, inducida por el cultivo y presión humana del territorio. Ello contrasta con focos donde el quejigo alcanza una elevada abundancia (Monte Umbría, Nuevo Baztán, Valdealcalá y Villar del Olmo). En el N y en el cuadrante SE está muy próximo a alcanzar un límite local de distribución, si no fuera por la aparición dispersa de algunos pies. El IOP del quejigo es casi tres veces menor al de la encina y su área de distribución experimenta una evidente reducción (casi desaparece en los páramos cultivados), sin embargo existen dos focos donde mantiene una mayor implantación (Monte Umbría y Nuevo Baztán). Ello pone de manifiesto que en estos sectores de la Baja Alcarria, el quejigo sigue ocupando todavía importantes espacios, aunque localizados en ámbitos más acotados (laderas resguardadas y con umbría acentuada). En otras unidades geográficas entra en competencia natural con la encina por razones bioclimáticas (por mayor evapotranspiración potencial que en la Alta Alcarria) y en competencia antrópica («desleal», podría decirse, por el favorecimiento humano de la encina). Como en el caso de Utande, se estima que si se dieran en el futuro condiciones de muy baja presión agraria en laderas, el quejigo ampliaría también su área de distribución en Ambite. Y si, en el caso improbable de que cesase el cultivo, en áreas endorreicas del páramo, el quejigo a largo plazo adquiriría más protagonismo que la encina.

Los mapas de $4 \mathrm{~km}^{2}$ expresan aún con ciertos detalles geográficos la diferente implantación en ambas cuadrículas, pues muestran en Ambite dos recintos de ausencia y cinco en donde su presencia es la mínima posible ("Localizada rarísima a muy rara"), categorías que no se dan en Utande. Por 

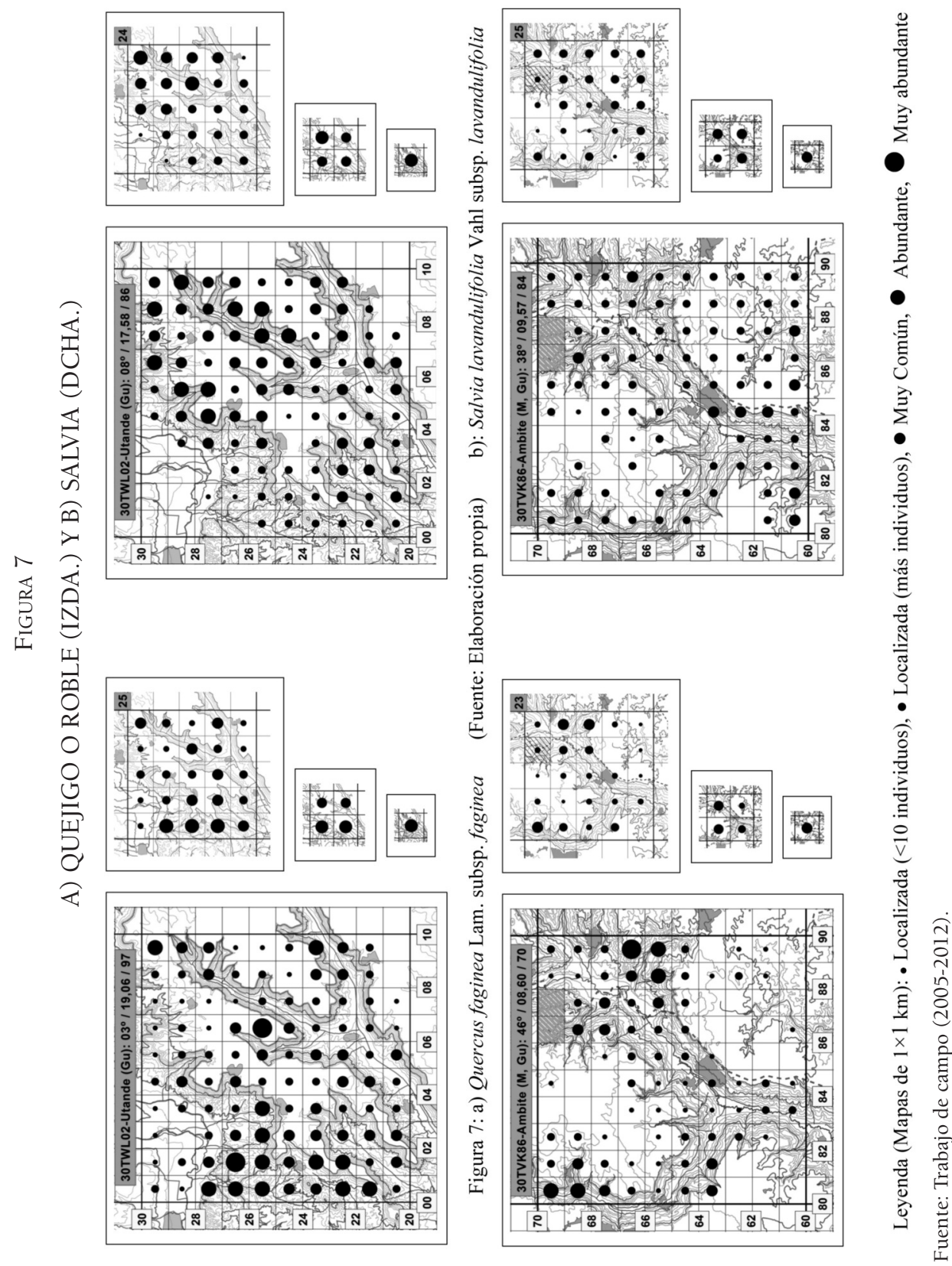

Estudios Geográficos, Vol. LXXVII, 280, pp. 81-113, enero-junio 2016 ISSN: 0014-1496, eISSN: 1988-8546, doi: 10.3989/estgeogr.201604 
contra, en esta cuadrícula se alcanza la categoría "Abundante" hasta en tres recintos, nivel que no se alcanza en Ambite, pese a los focos de gran abundancia en cuadrículas de $1 \mathrm{~km}^{2}$. Los mapas de $25 \mathrm{~km}^{2}$ evidencian claramente esta disparidad en la ocupación de ambas cuadrículas e, incluso, en Ambite más desigualdades internas (aparecen tres categorías diferentes: "Localizada muy rara" a "Localizada poco común"). Por último, la resolución de síntesis global expresa para Utande una ocupación "Muy común", frente a "Localizada común" en Ambite.

Pese a las transformaciones antrópicas del paisaje vegetal actual, puede deducirse una mayor decantación bioclimática del quejigo por el piso supramediterráneo.

$12^{\circ}$ ) Salvia lavandulifolia Vahl subsp. lavandulifolia (Salvia, figura 7b). Este otro sufrútice, con una autoecología similar a la de los otros arbustillos, se presenta en salviares (destaca el hallado en 30TWL0926), salviar-esplegares, lastonar-salviares, aliagares y otros matorrales, pero también bajo dosel quercíneo, en bosques y monte bajo. Ocupa las laderas menos soleadas (en Utande, sobre todo, los tramos altos con más recurrencia de incendios), bordes de páramo y escarpes, y ya menos laderas soleadas, páramos y lomas, desapareciendo en los sustratos ácidos y complejo fluvial (como tomillo común y espliego). En Utande su abundancia tiene una distribución desigual, pues domina ampliamente en las laderas del cuadrante $\mathrm{N}$ y NE, con unos niveles equiparables a los de aliaga y lastón, en un área donde el pastoreo e incendios han tenido mayor intensidad y frecuencia. Por muy poco no se configura un límite local de distribución en el extremo NW. Sin embargo, en el resto del territorio presenta una ocupación más modesta, equiparándose casi a la propia de tomillos, espliego o ge del campo. En Ambite desciende casi a la mitad los valores de IOP, aunque mantiene una frecuencia similar. Aquí se aprecia mejor la afección que produce la actividad agrícola en páramos y, salvo en algunas laderas más resguardadas a la insolación, presenta niveles de ocupación manifiestamente menores que los arbustos anteriores.

Los mapas de $4 \mathrm{~km}^{2}$ exhiben una casi total ocupación por parte de la salvia. El de Utande sintetiza muy bien, pero sin perder los detalles fundamentales, su dispar distribución. La comparación con Ambite muestra sobradamente la menor ocupación en esta cuadrícula. Y, aunque con menor nitidez, las resoluciones más groseras también alcanzan para marcar las diferencias apuntadas. Se constata un gradiente decreciente N-S de la salvia en La Alcarria Occidental, debido sobre todo al factor bioclimático. 


\section{CONCLUSIONES}

Pese a que se han tratado las plantas con mayor ocupación territorial y, por los estudios de vegetación efectuados en trabajos anteriores eran esperables una amplia presencia y abundancia de las mismas, las distribuciones detectadas son novedosas por ser desconocidas hasta ahora sus configuraciones concretas. Además, las valoraciones fitogeográficas expuestas ponen de manifiesto que, a escala local, son bastantes los matices y caracteres diferenciales destacables, más allá de su presumida gran implantación.

En los mapas corológicos se constata que la amplitud de la distribución geográfica de una planta, expresada por la frecuencia de aparición, no se ajusta al grado de ocupación en un territorio, expresada por el IOP. Ello es especialmente notable en los casos del tomillo común, salvia y, sobre todo, del romero.

Sorprende constatar cómo en unidades territoriales regulares de poca extensión (100 km²), con factores geográficos bastante o muy homogéneos y con biótopos repetitivos, hay distribuciones con rupturas tan abruptas que oscilan desde la clara ausencia hasta la elevada o máxima abundancia. Es el caso del romero (en ambas cuadrículas) y del quejigo (en Ambite). Estos dos casos constituyen modelos tan especiales como singulares, y su detección aporta conocimiento de nuevas realidades fitogeográficas y abren otras vías de investigación.

En concurrencia con el análisis de los factores geográficos, las distribuciones detectadas a escala local constituyen datos que contribuyen a clarificar y calibrar mejor el carácter, sentido y alcance que las alteraciones humanas del territorio han tenido históricamente en Ambite y Utande. Los casos de la encina, lastón, romero y quejigo, aunque no los únicos, son especialmente reveladores al respecto.

El análisis comparado de las distribuciones entre ambas cuadrículas no sólo discrimina el sentido de bastantes gradientes naturales de las plantas analizadas, sino que también los localiza con gran detalle geográfico y los cifra cuantitativamente en términos de abundancia y frecuencia.

El rastreo sistemático y exhaustivo del territorio que implican los planteamientos técnico-metodológicos propuestos permiten conocer con detalle local realidades fitogeográficas muy poco detectadas, con pocos antecedentes en la bibliografía española y, por ello, muy mal conocidas. Esta labor es útil, entre otras cuestiones, para:

a) Disponer de bases de datos con niveles de detalle y calidad apropiados para evidenciar diferencias ecológicas con escala adecuada para la ges- 
tión ambiental y del territorio, pues mejoran el nivel de conocimientos fitogeográficos y precisan con mayor detalle los autoecológicos. Además, por ser actualizables en el tiempo, posibilitan avanzar en estudios sobre dinámica y evolución de comunidades vegetales, de cambios en el paisaje, de impactos y riegos ambientales, entre bastantes aplicaciones más.

b) Usar alternativamente hasta cuatro resoluciones espaciales $(1 \times 1,2 \times 2$, $5 \times 5$ y $10 \times 10 \mathrm{~km}$ ), propiciando ajustes informativos escalonados desde los fines generales a los de detalle y permitiendo comparaciones geográficas entre territorios con un muy alto grado de certeza y operatividad cuantitativa. Los comentarios efectuados al respecto sobre la elocuencia expresiva inherente a cada tipo de resolución son de especial interés para la Cartografía Corológica.

c) Posibilitar que los resultados se valoren y cifren no sólo ambientalmente, sino también en términos de recursos naturales y, por tanto, económicos.

d) Aportar información relevante para efectuar y ajustar eventuales modelos predictivos de distribución de plantas en otros ámbitos de La Alcarria Occidental.

Tras el trabajo efectuado, estos dos artículos han pretendido hacer una primera presentación reveladora del alcance del método establecido de análisis florístico a escala de detalle en ámbitos locales. Sin embargo, quedan todavía muchos datos de interés fitogeográfico, interpretaciones, cálculos y resultados por exponer. Igualmente, es posible el diseño de bastantes aplicaciones. Esperamos ir dando cuenta de ello en futuras publicaciones.

\section{BIBLIOGRAFÍA}

Anthos (2013): Sistema de información de las plantas de España, Madrid, Real Jardín Botánico, CSIC/Fundación Biodiversidad, recurso electrónico en www.anthos.es, última consulta, septiembre de 2013.

Bartolomé, C., Rejos, F. J. y Álvarez, J. (2002): Flora y vegetación de la Baja Alcarria de Guadalajara, Madrid, Unión Fenosa, 204 pp.

Bellot, F., Ron, M. E. y Carballal, R. (1979): "Mapa de la vegetación de la Alcarria Occidental", Trabajos del Departamento de Botánica y Fisiología Vegetal, 10, pp. 3-32.

Bolòs, O. de (eds.) (1985 y ss.): Atlas corològic de la flora vascular dels Països Catalans, ORCA, Barcelona, IEC, varios vols.

Brown, J. H., Stevens, G. C. y Kaufman, D. M. (1996): "The geographic range: size, shape, boundaries, and internal structure", Annual Review of Ecology and Systematics, 27 , pp. 597-623. 
Buendía, F. (2000): Principales especies pascícolas de las zonas templadas, Madrid, Fundación Conde del Valle de Salazar, 229 pp.

Costa, M. (1974): "Estudio fitosociológico de los matorrales de la provincia de Madrid", Anales Instituto Botánico Cavanilles, 31/1, pp. 225-315.

De La Cruz, M. (1994): "El paisaje vegetal de la cuenca del río Henares (Guadalajara)", tesis doctoral inédita, Universidad de Alcalá, 473 pp.

De Luis, M., Raventós, J. C., González-Hidalgo, J. C. y Sánchez, J. R. (2004): "Fire and torrential rainfall: effects on the perennial grass 'Brachypodium retusum'", Plant Ecology, 173/2, pp. 225-232.

García-Abad, J. J. (2006): "El inventario florístico con fines geográficos en C.U.T.M. de $1 \times 1 \mathrm{~km}$, Análisis de la riqueza vascular en La Alcarria Occidental y Mesa de Ocaña”, Serie Geográfica, 13, pp. 117-150.

García-Abad, J. J. (2015): "Abundancia relativa, frecuencia y riqueza de plantas vasculares a escala local, Metodología de Índices de Ocupación de la Flora (Aplicación a la Alcarria Occidental)", Estudios Geográficos, 76/279, pp. 499-530.

García-Abad, J. J., Gómez, M. y Rodríguez, V. M. (2009): “Cartografía detallada de plantas vasculares en un sector de la Alta Alcarria, Guadalajara, Utilidad en la detección de enclaves naturales de interés”, Lazaroa, 30, pp. 161-174.

González, F. (1997): Gramíneas pratenses de Madrid, Madrid, Comunidad de Madrid, $287 \mathrm{pp}$.

Gutiérrez, M. (coord.) (1994): Geomorfología de España, Madrid, Editorial Rueda, $526 \mathrm{pp}$.

I.N.E. (2013): Instituto Nacional de Estadística, recurso electrónico en www.ine, última consulta realizada en septiembre de 2013.

Izco, J. (1972): "Coscojales, romerales y tomillares de la provincia de Madrid", Anales Instituto Botánico Cavanilles, 29, pp. 70-108.

Izco, J. (1983): "Discriminación florística de los sectores Manchego y Celtibérico-alcarreño (Provincia corológica Castellano-maestrazgo-manchega)", Anales de la Real Academia de Farmacia, 49/4, pp. 779-794.

Mata, R. y Sanz, C. (dirs.) (2003): Atlas de los paisajes de España, Madrid, Ministerio de Medio Ambiente, Universidad Autónoma de Madrid, 683 pp.

Meaza, G. (ed.) (2000): Metodología y práctica de la Biogeografía, Barcelona, Editorial del Serbal.

Meaza, G. y Cuesta, M. J. (2010): "Fitoindicación/fitoacción ambiental y territorial, Ensayo de aplicación en la Reserva de la Biosfera de Urdaibai (País Vasco), Boletín de la AGE, 54, pp. 99-123.

Panareda, J. M., Carbó, S., Alemany, F. y Torallas, J. (1997): “Cartografía corológica del Delta del Ebro, Planteamiento y primeros resultados", XV Congreso de Geógrafos Españoles, Santiago de Compostela, Asociación de Geógrafos Españoles, pp. 181-189.

Panareda, J. M. y Nuet, J. (1993-94): "Tipología y cartografía corológica de las plantas vasculares de Montserrat (Cordillera Prelitoral Catalana)", Revista de Geografía, XXVII-XXVIII, pp. 33-58. 
Parenti, L. R. y Malte, C. E. (2009): Comparative Biogeography. Discovering and classifying biogeographical patterns of a dynamic earth, Berkeley and Los Angeles, University California Press, 295 pp.

Portero, J. M., Aznar, J. M., Díaz, M., Pérez, A., Gallardo, J., González, F., Aguilar, M. J. y Leal, M. C. (1990): Mapa geológico de España. Escala 1:50.000. 486 (21-19), Jadraque, Madrid, Instituto Tecnológico y GeoMinero de España, 77 pp.

Rivas-Martínez, S. (2007): "Mapas de series, geoseries y geopermaseries de vegetación de España (Memoria del mapa de vegetación potencial de España). Parte I", Itinera Geobotanica, 17, pp. 5-436.

Rivas-Martínez, S., Díaz, T. E., Fernández-González, F., Izco, J., Loidi, J., Lousâ, M. y Penas, A. (2002): "Vascular plant communities of Spain and Portugal. Addenda to the syntaxonomical checklist of 2001", Itinera Geobotanica, 15, pp. 5-922.

Rivas-Martínez, S. y Loidi, J. (1999): "Bioclimatology of the Iberian Peninsula", en S. Rivas-Martínez, J. Loidi, M. Costa, T. E. Díaz y A. Penas (eds.), "Iter Ibericum A. D. MIM", Itinera Geobotanica, 13, pp. 41-47.

Ron, M. E. (1970): "Estudio sobre la vegetación y flora de La Alcarria", tesis doctoral inédita, Universidad Complutense de Madrid, Facultad de Ciencias (sección biológicas).

SIVIM (2013): Sistema de información de la vegetación ibérica y macaronésica, Madrid, Ministerio de Educación y Ciencia, recurso electrónico en www.sivim.info/sivi/, última consulta, septiembre de 2013.

Varela, J. M. (coord.) (1996): Estudio de la vegetación de los ríos carpetanos de la Cuenca del Jarama, Madrid, CEDEX.

Vera, J. A. (ed.) (2004): Geología de España, Madrid, Sociedad Geológica de España, IGME, 890 pp.

Fecha de recepción: 3 de abril de 2014.

Fecha de aceptación: 23 de abril de 2015.

\section{RESUMEN}

Se aplica la Metodología de Índices de Ocupación de la Flora, presentada en un artículo anterior, en dos cuadrículas de $100 \mathrm{~km}^{2}$ pertenecientes a La Alcarria Occidental, pero localizadas en sectores diferentes (Ambite, 30TVK86, y Utande, 30TWL02), con objeto de conocer y comparar las distribuciones geográficas de la presencia y abundancia de plantas vasculares a escala local. Se exponen ampliamente los factores geográficos diferenciales que inciden en la ocupación de la flora. Se presentan el método de análisis y la elaboración de la cartografía corológica para cuatro resoluciones cartográficas diferentes $\left(1,4,25\right.$ y $\left.100 \mathrm{~km}^{2}\right)$. Se muestran y se comentan fitogeográficamente los resultados de los doce taxones con mayor IOP en el conjunto de las dos cuadrículas: Genista scorpius, Quercus ilex subsp. ballota, Thymus vulgaris, Helianthemum cinereum subsp. rotundifolium, Brachypodium retusum, Thymus zygis subsp. 
sylvestris, Lavandula latifolia, Dactylis hispanica, Rosmarinus officinalis, Koeleria vallesiana, Quercus faginea y Salvia lavandulifolia.

Palabras Clave: Cartografía corológica; escala local; Geografía de las plantas; Índice de ocupación de la planta; La Alcarria Occidental

\section{Abstract}

The method for performing Floral Cover Indices (FCI), presented in a previous article, is applied to two $100 \mathrm{~km}^{2}$ U.T.M. grid cells (30TVK86, Ambite and 30TWL02,Utande). They are located in different sectors of the natural region of Western "La Alcarria". The goal is to know and compare distributions of presence and abundance of vascular plants at local scale. Geographical factors affecting cover of the flora is widely exposed. Analysis method and chorological maps drawing with four spatial levels $\left(1,4,25\right.$ and $\left.100 \mathrm{~km}^{2}\right)$ are presented. Results of the twelve taxa with the highest FCI in the set of two grid cells and phytogeographical interpretations are shown: Genista scorpius, Quercus ilex subsp. ballota, Thymus vulgaris, Helianthemum cinereum subsp. rotundifolium, Brachypodium retusum, Thymus zygis subsp. sylvestris, Lavandula latifolia, Dactylis hispanica, Rosmarinus officinalis, Koeleria vallesiana, Quercus faginea and Salvia lavandulifolia.

Key words: Chorological mapping; local scale; Plant Geography; Floral Cover Index (FCI); Western "La Alcarria" 